\title{
IMIGRACÃO E ESCOLARIDADE EM DOIS BAIRROS DA CIDADE DE SÃO PAULO
}

Carmen Soledad Aurazo de Watson ${ }^{1}$

Resumo: Nesse trabalho aprofunda-se temas relativos à escolaridade de populações de imigrantes, que ocupam dois bairros centrais da cidade de São Paulo. No trabalho original se observou importante ocupação desses fluxos no bairro bem como de estudantes estrangeiros nas escolas da região. O objetivo desse trabalho é identificar as mudanças ocorridas desde 2015, ano da pesquisa, até 2019, no contexto de aumento de imigrantes e refugiados que chegaram na cidade recentemente. Se estudam os contingentes de população imigrante, inserção e origem, aspectos da demanda escolar pelos imigrantes e dos níveis de aproveitamento no ensino no contexto escolar local. Se usam informações secundárias e questionários abertos aplicados a professores e vice-diretores, para constatar a percepção que tem da situação particular do contingente estrangeiro na escola, de um lado, e às mães dos estudantes, a percepção que as famílias têm da escola e escolaridade dos filhos, de outro. Os resultados mostram a dinamicidade dos processos sociais, contra o apontado na pesquisa anterior, se observou leve aumento dos estrangeiros na região e diminuição em um dos bairros; o baixo desempenho escolar dos estrangeiros confirma os desafios no processo de escolaridade desses segmentos para professores e gestores; e, as condições da educação da população escolar boliviana e peruana, em particular, pode estar sendo afetada pela situação de vulnerabilidade geral das famílias.

Palavras-chave: Imigração. Escolaridade. Estudantes latino-americanos

Abstract: This work deepens themes related to the schooling of immigrant populations, occupying two central districts of the city of São Paulo. In the original work, it was observed important occupation of these flows in the neighborhood as well as foreign students in the schools of the region. The objective of this work is to identify the changes that have occurred

\footnotetext{
${ }^{1}$ Socióloga, con Doctorado en Geografía Humana en la Universidad de São Paulo - USP
} 
since 2015, year of Research, until 2019, in the context of an increase in immigrants and refugees who arrived in the city recently. The quotas of immigrant population, insertion and origin, aspects of school demand by immigrants and education performance in the local school context are studied. Using secondary information and open questionnaires applied to professors and managers, to verify the perception of the particular situation of the foreign contingent in the school, on the one hand, and to the mothers of the students, the perception that families have of schooling of the children, on the other. The results show the dynamism of the social processes, against the one pointed out in the previous research, it was observed a slight increase of foreigner students in the region and a decrease in one of the districs; The low school performance of foreigners confirms the challenges in the schooling of these segments for teachers and managers; And, the conditions of education of the Bolivian and Peruvian school population, in particular, may be affected by the situation of general vulnerability of families.

Key-words: Immigration. Schooling. Latin American Students.

\section{Introdução}

No presente artigo, o propósito é aprofundar indagações apontadas em trabalho anterior, realizado em 2016, no tocante à escolaridade e imigração em dois distritos da área central da cidade de São Paulo, Brasil $^{2}$. Embora a temática sobre imigração e refúgio são amplamente abordados na imprensa e na área acadêmica, a questão educativa na perspectiva da diversidade está sendo incorporada na problemática populacional nacional, devido ao aumento dos fluxos migratórios no país recentemente. (RODRIGUES, 2017; MAZZA, 2016; BAHIA, 2016).

Estudos sobre a relação migração e educação em diversas comunidades de estrangeiros apontam a processos maiores como

${ }^{2}$ WATSON, C. de - Imigrantes Latinos e Escolas Públicas em dois Bairros da Cidade de São Paulo: Bom Retiro e Brás In Identidade e Diversidade Cultural na América Latina. Lima, E; Watson, C. de (Org.) Porto Alegre, RS: Editora Fi 2017 
inclusão, socialização. As comunidades de estrangeiros são objeto de desigualdades no acesso a bens e serviços que permita boas condições de vida no país de destino. A pobreza, dificuldade de regularização de documentação, fixação de residência e o idioma, entre outros, são fatores causantes apontados. A isso se acrescenta aspectos específicos, como políticas públicas na área da educação não inclusivas ou ineficazes, separação entre pais e filhos (LESLIE, 2017; ALVITES, 2001), contextos de racismo na comunidade e na escola (HAMANN, 2010), com impacto na escolaridade dos estudantes estrangeiros.

Nesse trabalho se estuda as mudanças ocorridas no período 20152019 aprofundando as questões observadas no trabalho original. Pretendese apontar aspectos da ocupação do espaço e a participação da população imigrante, bem como do segmento escolar nos bairros selecionados; identificar se houve mudanças na interação escolas-famílias visando à promover, de um lado, a participação da comunidade de estrangeiros no ambiente escolar; e, de outro, como é o tratamento dos estrangeiros pelos professores e gestores, e, de que forma esses fatos se refletem no desempenho escolar dos estudantes; qual a percepção dos pais em relação ao ensino dado nas escolas dos filhos, entre outros.

Além da Introdução, esse texto consta de cinco seções: na primeira, "Imigração no Brasil contemporâneo" serão apresentados aspectos gerais da migração no país e na cidade e seu impacto na área selecionada; na segunda, "Os bairros Bom Retiro e Brás e os estudantes estrangeiros" é identificada a presença dos estudantes estrangeiros na região e sua demanda escolar; na terceira, "Estudantes estrangeiros e o ambiente escolar local", são apresentados aspectos da dinâmica escolar, a relação professores- estudantes e a percepção dos pais da educação dos filhos; na quarta, "Resultados da Pesquisa: indicadores do desempenho escolar" se analisam aspectos do desempenho escolar; são analisados 
as avaliações das disciplinas português e matemática; e, por último, as "Considerações Finais".

\section{Imigração no Brasil contemporâneo}

Entre 2000 e 2015, segundo a Tabela 1, um total de $880 \mathrm{mil}$ estrangeiros foram registrados no país ${ }^{3}$. Registrado significa que consta no Registro Nacional de Estrangeiro - RNE, que regulariza a situação de residência do estrangeiro no país.

Dos doze países da tabela, cinco são da região latino-americana. A Bolívia ocupa o primeiro lugar. Depois da Bolívia vem os Estados Unidos, que junto com o Portugal, Alemanha, França e Itália são países europeus com um alto contingente de imigrantes no Brasil, mas que não são objeto de estudo nesse trabalho. Em seguida aparecem a Argentina e a Colômbia, com longo histórico de deslocamento; a Colômbia desde a década de 1960 (pela guerrilha das Forças Armadas Revolucionárias da Colômbia-Farc). Peru praticamente duplicou seu crescimento a partir da anistia de 2009 e posteriormente com o Acordo Bilateral Brasil-Peru (Mercosul), de 2012. Por esta data o Brasil recebe os haitianos e mais recentemente os Venezuelanos ${ }^{4}$.

\footnotetext{
${ }^{3}$ Observatório das Migrações em São Paulo, NEPO/Unicamp. A Polícia Federal outorga, via RNE, residência transitória, documento válido por dois anos, depois pode solicitar a residência permanente.

${ }^{4} \mathrm{O}$ êxodo na Venezuela merece ser estudado para identificar as causas, considerando que em décadas anteriores foi um importante país receptor de migrantes.
} 


\section{Tabela 1 - Nacionalidade de estrangeiros registrados no Brasil}

\section{Nacionalidade de estrangeiros registrados}

Foram registrados 880 mil estrangeiros no país entre 2000 e 2015

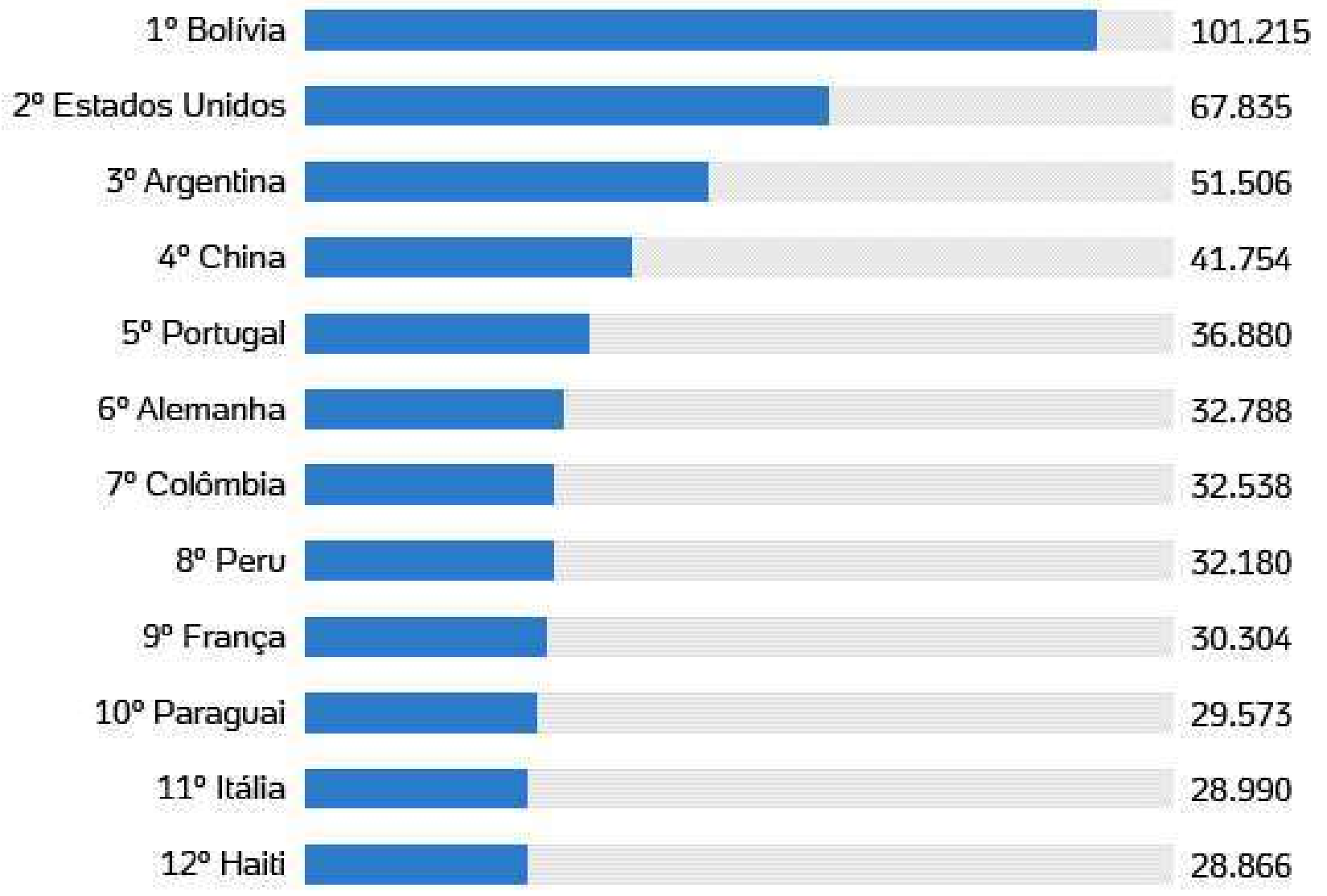

"RNEs emitidos de 2000 a 2015

O Haiti é um país caribenho que aparece recentemente entre os primeiros da lista, que sofre um terremoto em 2010, conseguindo seu ingresso no país com visto humanitário. A Venezuela, que não aparece na lista, é um dos últimos países com um imenso êxodo de sua população, por causa de uma crise econômica e política que lhes permite ser solicitantes de visto de refúgio. Nesse deslocamento também deixam a Venezuela contingentes de outras nacionalidades que imigraram em décadas anteriores quando o país estava em amplo desenvolvimento. Os 
colombianos que retornam a seu país, da Venezuela, superaram o milhão de pessoas até o começo de 2018, constituindo um desafio para o governo local e nacional 5 . No Brasil, os venezuelanos, iniciam sua chegada pela fronteira de Roraima e Amazonas, desde 2016, fluxo que se intensifica em 2017 e 2018. Um número menor de venezuelanos chega a São Paulo por essa via e outros diretamente por avião. (SILVA, 2018).

Outra fronteira de permanente circulação de pessoas é a tríplice fronteira do estado de acre (Brasil-Bolívia-Peru). Se estima que entre 2010 e 2015 passaram por essa fronteira 37,864 haitianos, 5,196 senegaleses, 410 dominicanos, 22 colombianos, 14 nigerianos, 14 gambianos, 10 ganenses, entre outros. (COTINGUIBA, 2017, p. 121) A esses deslocamentos se sumam o de sírios, iraquianos, chineses, etc., por diversos motivos como guerras, mudanças climáticas, perseguições políticas, religiosas, etc., no âmbito global das migrações.

Com o impedimento de entrada dos países do Norte, pela crise econômica, os imigrantes retornam a seus países de origem ou se dirigem a outros países da região. Duas características são observadas nesse processo de migração na América Latina: uma mudança na direção dos fluxos, na direção Sul-Sul entre os países da América Latina e esses fluxos constituído mormente por refugiados de guerras, crises políticas, desastres naturais, dentre as novas modalidades de deslocamentos na contemporaneidade, pelo que se denominam "imigrações refugiadas". (BAENINGER et al., 2018, p. 13) ${ }^{6}$.

\footnotetext{
${ }^{5}$ Ver Informe do Banco Mundial a solicitude do Governo da Colômbia, baseado em dados quantitativos e qualitativos já existentes, identificados, coletados e analisados entre os meses de maio e julho de 2018. Migración desde Venezuela a Colombia: impactos y estrategia de respuesta en el corto y mediano plazo. Disponível em: https://openknowledge.worldbank.org/bitstream/handle/10986/30651/131472SP. pdf?sequence $=3 \&$ isAllowed $=y$ Acesso em nov $/ 2018$ ${ }^{6} \mathrm{http}: / /$ www.nepo.unicamp.br/publicacoes/livros/migracoes_sul_sul/migracoes_sul_ sul.pdf
} 
Brasil: o país que acolhe refugiados

O Brasil das últimas décadas é lugar de destino importante no processo de imigração e refúgio. Dois fatores destacam, a política de acolhimento e a situação da economia no momento. O Brasil tem se inserido na dinâmica da mobilidade internacional de refúgio, na medida em que a vinculação do estado brasileiro aos tratados internacionais de refúgio e a lei 9474/1997 (Estatuto Jurídico do Refugiado) estabelecem garantias que trouxeram novos povos para o Brasil. Por outro lado, entre 2003 e 2014, o Brasil se mostra como imune a crise mundial, com um crescimento econômico, a criação de mais de 14 milhões de empregos e uma relativa inclusão social. A expansão da presença brasileira na América do Sul, no Haiti e na África indicavam ao mundo pretensões diplomáticas específicas. (MAGALHÃES et al., 2018). Outros estudos constatam nos oito anos do governo Lula (2003-10) a realização de uma política externa que se diferenciou por construir pontes com o mundo Árabe, com uma dimensão política e bilateral de relevo, marcando a busca pela diversificação de parcerias e pelo retorno à cooperação sul-sul (RODRIGUES, 2018, pp. 313)

Apenas uma parte dos solicitantes de refúgio são atendidos, assim se menciona que apenas 28,866 haitianos conseguiram RNE (segundo a Tabela 1, acima), dos 85,084 haitianos que entraram no Brasil entre 2010 e 2015. (COTINGUIBA, op. cit.).

\section{São Paulo: Diversidade étnica e cultural}

A cidade de São Paulo, que é a maior metrópole do país, concentra não apenas a maior quantidade de população imigrante como também a maior diversidade étnica e cultural, com pessoas de grande número 
de países do mundo. Para ter uma ideia do volume de imigrantes na cidade, em 2010 chegaram ao estado de São Paulo 81,682 imigrantes ${ }^{7}$. Aos fluxos mais antigos de italianos, japoneses, judaicos seguem os de coreanos e bolivianos, e mais recentemente de outras nacionalidades, como haitianos, sírios, senegaleses, peruanos, venezuelanos, etc., que se inserem na sociedade em função das oportunidades que a cidade lhes oferece no processo de mudança que vem experimentando no contexto global, de uma cidade industrial a uma cidade com predominância do setor financeiro e de serviços, onde as atividades terciárias e a informalidade vêm ocupando lugar central. Nesses espaços os imigrantes se instalam segundo suas condições sociais e econômicas.

As Cidades de São Paulo e São Bernardo do Campo são as mais procuradas pelo novo contingente de sírios, as tradicionais dos síriolibaneses no Brasil. Segundo o Comitê Nacional para os Refugiados (CONARE) existem 3,460 sírios vivendo no Brasil entre 2010-2015. (Rodrigues, 2018, op.cit.). No estudo sobre trabalho e espacialidade, referente às comunidades boliviana, haitiana e turca, se consolida a preferencia de São Paulo como um dos destinos para imigrantes e refugiados internacionais. (MAGALHÃES, 2018).

\section{Os distritos Bom Retiro e Brás - Tendências recen- tes na ocupação do espaço e na escolarização dos imigrantes 2015-2019}

Nessa seção se apresenta o quadro da evolução da ocupação dos bairros pela população em foco, desde 2016, com destaque das atividades econômicas estabelecidas. Essa data (em que ocorre impeachment na

\footnotetext{
${ }^{7}$ Segundo o IBGE, São Paulo junto com os Estados de Paraná e Minas Gerais receberam mais da metade dos imigrantes dos últimos dez anos $(148,529)$, seguidos por Rio de Janeiro e Goiás. (Rodrigues, 2017).
} 
presidência do país) é importante, marca o ponto de inflexão nas políticas sociais inclusivas que estavam sendo implementadas pelos governos vigentes e passam a serem substituídas por outras de cunho estritamente neoliberal pelo governo que assume o poder. Em seguida, a população escolar e os estudantes estrangeiros nos bairros e aspectos do ambiente escolar local.

Bom Retiro e Brás: bairros de imigrantes e refugiados

Como constatado em estudo anterior e em outras pesquisas, nesses bairros, observa-se, junto com a presença desse contingente de estrangeiros, o aumento de outros grupos já existentes e a emergência de novos grupos de imigrantes. A paisagem urbana também sofre mudanças resultado das formas de ocupação e das atividades económicas realizadas pelos novos moradores.

Assim, visualizam-se nas atividades econômicas e culturais diversas nacionalidades: os bolivianos, coreanos e chineses (se consolidam nas atividades na confecção e comércio de costura-Feira da Madrugada, bairros inteiros da região onde se vende os produtos confeccionados pelas oficinas de costura); os haitianos incrementam as interações do comercio popular, oferecendo nas ruas da região aparelhos como celulares, relógios, etc. Se expandem atividades étnicas, como a gastronomia e serviços dos salões de beleza. (MAGALHÃES, op. cit.). A rua Coimbra é reconhecida como um enclave étnico, junto com o comércio de produtos típicos andinos, se instalaram restaurantes, salões de beleza étnica e é ponto de reunião de diversos grupos da comunidade boliviana com fines culturais e de apoio social. O Consulado da Bolívia tem uma sede próximo da rua Coimbra, para melhorar o acesso aos serviços por 
parte da comunidade boliviana. Os peruanos, de atividades comerciais e de artesanato, emergem na gastronomia nos últimos oito anos (mais de dez restaurantes se instalam na região ou em bairros próximos como Santa Ifigênia e República, chegando a mais de quarenta na cidade, e a venda de marmitas de comida típica que constitui fonte de renda de muitas famílias peruanas). (WATSON, 2017). Africanos e sírios, com o aumento de igrejas e de restaurantes de comida típica.

A efervescente dinâmica econômica observada na região em foco e em outras regiões está mudando a paisagem urbana e contribuindo para reativar a economia da cidade, com participação em atividades econômicas formais e informais, no processo de desconcentração industrial, expansão do setor terciário da cidade nas últimas décadas e consolidação como centro das atividades financeiras no país e de seu papel como cidade global no novo arranjo da economia globalizada. (MAGALHÃES, op. cit.).

$\mathrm{Na}$ pesquisa original se constatou aumento da população dos bairros do Bom Retiro e Brás, entre 2010 e 2015. Considerando as mesmas taxas de crescimento anual do período anterior (em torno de 1,52 para Bom Retiro e 2,45 para Brás), a população estimada em 2018 para Bom Retiro e para Brás é de 39,540 e 32,852, respectivamente (SEADE, 2018). Se observa um leve crescimento da população total na região.

A ocupação do espaço ocorre de forma heterogênea. A inserção da maioria da população estudada se produz em condições precárias - expressa no aglutinamento de várias famílias em uma unidade de moradia, no aumento de famílias estrangeiras em prédios de invasão ${ }^{8}$ - e

\footnotetext{
${ }^{8}$ Das 39 famílias entrevistadas, duas mães peruanas declararam ter mudado da casa compartilhada com familiares para um quarto em um prédio de invasão, por causa de perda de emprego do marido.

Em incêndios em prédios de invasão, como o de maio/2018 no centro de São Paulo, de 372 moradores $10 \%$ eram estrangeiros; vários dos quais foram encontrados entre os falecidos. Disponível em:
} 
nos baixos índices sociodemográficos que caracterizam a região, mas que eles priorizam como locais de moradia pela proximidade aos postos de trabalho e a gratuidade da oferta de serviços como unidades de saúde e educativas. (WATSON, op. cit.).

Embora se constate que os novos fluxos se estabelecem em bairros periféricos da cidade (Guaianases, Parque Peruche, Guarulhos, Ermelino Matarazzo, Parque Novo Mundo, São Miguel Paulista, etc.), os bairros da região central (Bom Retiro, Brás, Sé, Pari, Santa Ifigênia, etc.) ainda são procurados pelos imigrantes antigos e recentes de baixa condição econômica. ${ }^{9}$

\section{Estudantes estrangeiros nos bairros Bom Retiro e Brás 2015-2019}

\section{Antecedentes}

A pesquisa realizada em 2016, com o intuito de estudar a integração dos imigrantes no ambiente educativo, evidenciou resultados importantes, focalizou os estudantes estrangeiros com ênfase nos bolivianos, ainda a língua do país natal sendo percebida pelos docentes e gestores como um dos problemas que interfere na aprendizagem e a baixa participação das famílias nas atividades das escolas. Tendo como pano de fundo essas informações, nessa seção apresentamos os resultados encontrados no período 2015-2019

A população escolar total nos bairros sofreu aumento de $3,28 \%$ no Bom Retiro e de 3,67\% no Brás, passando de 9.739 para 10.058 no Bom Retiro, e de 8.343 para 8.649 no Brás. (SEADE, 2018).

https://www1.folha.uol.com.br/cotidiano/2018/05/incendio-de-grandes-proporcoesatinge-um-edificio-no-largo-do-paissandu.shtml

${ }^{9}$ Silva, S.A. da - Bolivianos em São Paulo: entre o sonho e a realidade. Acesso em: ab/2019. Disponível em: http://www.scielo.br/scielo.php?script=sci arttext\&pid=S0103-40142006000200012 
Considerando o período curto da pesquisa entre 2015 e 2019, se percebe que houve aumento semelhante entre população total e a população escolar nos bairros em foco, constatando-se a permanência da mesma proporção, em torno do $26 \%$, da população escolar com relação à população total nos bairros, ao longo do período.

Pesquisa de campo - Aspecto metodológicos

O universo de estudo é formado pelas escolas da pesquisa anterior, nove escolas da rede pública municipal e estadual da região. Entrevistas com as famílias e professores e gestores das escolas às que se aplica questionários abertos.

Os temas abordados na pesquisa com os Coordenadores Pedagógicos e/ou diretores:

Nessa parte constam os temas relativos à pesquisa anterior: nacionalidade, a língua falada, os principais problemas apresentados, atividades que a escola oferece às famílias e a participação dos estudantes e dos pais de família nas escolas. Os itens que se adicionam nessa pesquisa: assistência dos estudantes às aulas e permanência na escola e a percepção de docentes e gestores do contexto atual no país; e, a percepção dos pais respeito da escolaridade de seus filhos, assim como a qualidade do ensino.
Diminuição da presença dos estudantes na região e leve aumento dos estrangeiros

A alta porcentagem de estudantes estrangeiros, encontrada nas 
escolas em foco em 2015, e o aumento recente do fluxo de imigrantes internacionais no país e na cidade de São Paulo induzia a prever alto aumento dos estudantes estrangeiros nas escolas dos bairros selecionados. Os dados para 2019, Tabela 2, revelam uma dinâmica interessante mostrando um novo rearranjo da ocupação escolar tanto dos estudantes no geral quanto dos estrangeiros. Assim:

- Diminuição do total de estudantes nos dois bairros, da ordem do $24 \%$ entre 2015 e 2018 , que representa quase um quarto de sua população em relação a 2015. Esse resultado é influenciado pela perda de 34,71\% dos estudantes no Brás. No entanto, o Bom Retiro apresenta pequeno incremento de $4,7 \%$ de estudantes.

- Nesse contexto, os estudantes estrangeiros apresentam um pequeno crescimento nos dois bairros em conjunto, de 5,5\%; que expressa tendência oposta à encontrada na população escolar total, isto é, uma diminuição da população de estudantes estrangeiros, 2,81\%, no Bom Retiro contra um aumento de 10,6\% no Brás.

Esse rearranjo na população de estudantes estrangeiros se expressa na diminuição relativa no Bom Retiro, que passa de $42,5 \%$ a $39,81 \%$ e no aumento relativo no Brás, de 24,24 a 41,07\%.

Os dados de decréscimo podem estar indicando uma diminuição da procura ou uma diminuição da oferta de vagas pelas escolas dos bairros. Diminuição da procura pode estar associada a deslocamento da população para outros bairros próximos. Ver a seguir o tipo de demanda por escolaridade.

\section{Mudança na demanda escolar dos estudantes estrangeiros}

As mudanças ocorridas na população escolar estudada, de 
diminuição, se expressam também em termos de procura por escolas de diferentes níveis de ensino. Assim:

- No Bom Retiro são cinco escolas, apenas uma escola apresenta perda no total de estudantes, no EF. No contingente dos estudantes estrangeiros, três escolas apresentam perda, sendo duas creches e uma EMEI.

- No Brás, são cinco escolas, quatro apresentam perda de estudantes, sendo apenas uma do EF que apresenta leve aumento de estudantes. Dessas, as escolas com perda de estudantes estrangeiros são uma creche e duas do EM.

Observa-se na região uma perda de estudantes, inclusive estrangeiros, nos níveis inicias do ensino (creches e EMEIs), com ênfase nos estrangeiros. No Brás tem uma diminuição importante dos estudantes nas três escolas do EM, pela mudança interna ocorrida nas escolas (mudança de regime, a ETEC oferece cursos técnicos, etc.). Essa diminuição se reflete no aumento relativo dos estudantes estrangeiros na escola de EM, Pe. Anchieta. Por outro lado, a alta proporção de estudantes nos cursos técnicos (ETEC Carlos de Campos) está indicando o interesse em uma formação para o mercado. Também foi confirmada pela escola Canuto do Val uma alta procura de estudantes estrangeiros do Bom Retiro no período 2016-2019. Essa escola oferece EM de ensino e está localizada próxima da região.

De forma geral, os dados abaixo apresentados relativos aos estudantes, inclusive os estrangeiros, nas escolas do Bom Retiro e Brás estariam apontando mudanças demográficas importantes, os níveis de crescimento da população total se mantiveram muito próximos ao do período anterior. (Seade, op. cit.).

A diminuição do total de estudantes no Brás, de $24 \%$, estaria indicando deslocamento da população do bairro para bairros próximos. 
No Bom Retiro também se observa diminuição do contingente de estrangeiros (aproximadamente 3\%). Se considerarmos os dados de ambos os bairros seriam em torno de $28 \%$ de diminuição de estudantes. Considerando que não teve diminuição de população total, se estima que o bairro esteja recebendo novos fluxos de imigrantes. 


\section{Tabela 2 - Escolas e estudantes nativos e estrangeiros Bom Retiro e Brás, SP 2015-2019}

\begin{tabular}{|c|c|c|c|c|c|c|c|c|}
\hline \multirow{2}{*}{$\begin{array}{l}\text { Distrito } \\
\text { Bom Retiro }\end{array}$} & \multicolumn{3}{|c|}{$\begin{array}{l}\text { Total de Estudantes } \\
\text { 2015-2019 }\end{array}$} & \multicolumn{3}{|c|}{$\begin{array}{l}\text { Estudantes estrangei- } \\
\text { ros 2015-2019 }\end{array}$} & \multicolumn{2}{|c|}{$\begin{array}{l}\text { \% Estrangeiros } \\
\text { no total de Es- } \\
\text { tudantes }\end{array}$} \\
\hline & 2015 & 2019 & $\begin{array}{l}\text { Taxa Va- } \\
\text { riação \% } \\
2015-19\end{array}$ & 2015 & 2019 & $\begin{array}{l}\text { Taxa Va- } \\
\text { riação \% } \\
2015-19\end{array}$ & 2015 & 2019 \\
\hline $\begin{array}{l}\text { EMEI Alceu } \\
\text { Maynard Araú- } \\
\text { jo }\end{array}$ & 210 & 270 & 28,6 & 90 & 125 & 38,9 & 42,86 & 46,29 \\
\hline $\begin{array}{l}\text { EMEI João } \\
\text { Theodoro }\end{array}$ & 250 & 256 & 2,4 & 125 & 82 & $(-34,4)$ & 50 & 39,53 \\
\hline $\begin{array}{lr}\text { Creche } & \text { Direct } \\
\text { Wilson } & \text { José } \\
\text { Abdala* } & \\
\end{array}$ & 125 & 144 & 15,2 & 78 & 55 & $(-29,49)$ & 62,4 & 38,19 \\
\hline $\begin{array}{l}\text { EE Marechal } \\
\text { Deodoro EF* }\end{array}$ & 800 & 759 & $(-5,12)$ & 320 & 300 & $(-6,25)$ & 40 & 39,526 \\
\hline $\begin{array}{l}\text { EE Prudente de } \\
\text { Morães EF }\end{array}$ & 1100 & 1172 & 6,55 & 440 & 468 & 6,4 & 40 & 39,932 \\
\hline Sub-total & 2485 & 2601 & 4,7 & 1053 & 1030 & $(-2,81)$ & 42,37 & 39,6 \\
\hline \multicolumn{9}{|l|}{ Brás } \\
\hline $\begin{array}{l}\text { Creche An- } \\
\text { tônia Moutri } \\
\text { Lamberga* }\end{array}$ & 173 & 141 & $(-18,5)$ & 69 & 49 & $(-28,99)$ & 39,88 & 34,75 \\
\hline $\begin{array}{l}\text { EE São Paulo } \\
\text { EM** }^{*}\end{array}$ & 1200 & 180 & $(-85)$ & 100 & 45 & $(-55)$ & 8,33 & 25 \\
\hline $\begin{array}{l}\text { EE Pe. Anchie- } \\
\text { ta EM }\end{array}$ & 2000 & 1525 & $(-23,75)$ & 600 & 830 & 38,3 & 30 & 54,4 \\
\hline $\begin{array}{l}\text { EE Eduardo } \\
\text { Prado EF* }\end{array}$ & 1000 & 1100 & 10 & 600 & 660 & 10 & 60 & 60 \\
\hline $\begin{array}{l}\text { ETEC Carlos } \\
\text { Campos*** }\end{array}$ & 2100 & 1601 & $(-24)$ & 200 & 152 & $(-24)$ & 9,52 & 9,49 \\
\hline Sub-total & 6473 & 4226 & $(-34,71)$ & 1569 & 1736 & 10,6 & 24,24 & 41,07 \\
\hline Total & 8958 & 6827 & $(-24)$ & 2622 & 2766 & 5,5 & 29,27 & 40,59 \\
\hline
\end{tabular}

Fonte: elaboração da autora

*2019 - Número estrangeiros declarado pela escola

** EE São Paulo, mudou para Escola em tempo integral

*** Ensino Médio-EM (425) + Curso Técnico $(1176)=1601$

Disponível em: https://www.melhorescola.com.br/ 
No Bom Retiro, o resultado de diminuição de estudantes nas escolas de nível inicial, estaria indicando deslocamento das famílias, ou mudança no comportamento reprodutivo das mulheres (diminuição do número de filhos por mulher). A Coordenadora Pedagógica da creche Antônia Moutri Lamberga declarou ter observado uma diminuição na procura de vagas na escola pelos pais bolivianos ao longo dos últimos anos. No Brás, observa-se um aumento dos estudantes estrangeiros (10\%), com um rearranjo na ocupação nas escolas, deslocamento de unas escolas e ocupação de outras. No entanto, as tendências maiores observadas, deslocamento de população, aumento de população migrante e comportamento reprodutivo do grupo feminino precisam de estudos mais aprofundados.

\section{Estrangeiros e nacionalidades nas escolas}

As escolas apresentam entre seis e 14 nacionalidades. Os bolivianos continuam a ser o grupo maior, porém está perdendo importância relativa no total de estrangeiros, conforme apontado. Assim, de quase 30\% para aproximadamente $15 \%$ na EMEI João Theodoro. Foi notório o aumento de paraguaios, colombianos e peruanos e a inclusão, pouco expressiva de novas nacionalidades, entre as quais a equatoriana, paquistanesa e venezuelana. Para ilustrar a variedade de nacionalidades, a seguir dados da EMEI João Theodoro. 
Tabela 3 - EMEI João Theodoro - Famílias estrangeiras com filhos na escola 2017

\begin{tabular}{l|l} 
Boliviana & 32 \\
\hline Paraguaia & 21 \\
\hline Peruana & 12 \\
\hline Chinesa & 2 \\
\hline Coreana & 1 \\
\hline Síria & 1 \\
\hline Paquistanesa & 1 \\
\hline Equatoriana & 1 \\
\hline Equatoriana-Boliviana & 1 \\
\hline Paraguaia-Boliviana & 1
\end{tabular}

Fonte: Cidade Aprendiz 2017

Escolas dos bairros e nacionalidade dos estudantes estrangeiros:

EE Pe. Anchieta: boliviana, paraguaia, haitiana, angolana, indiana, chinesa, síria e venezuelana, etc.

EE Marechal Deodoro: boliviana, peruana, argentina, coreana, camaronesa, palestina, etc.

EE Prudente de Moraes: boliviana, paraguaia, peruana, coreana, chinesa..."chegaram os venezuelanos".

Creche Antônia Moutri Lamberga, seis nacionalidades: boliviana, peruana, paraguaia, síria, angolana e chinesa.

EE Eduardo Prado, 14 nacionalidades: boliviana, peruana, paraguaia, colombiana, haitiana, síria, egípcia, chinesa, africana, venezuelana e outras. 


\section{Estudantes estrangeiros e o ambiente escolar local}

\section{Políticas públicas e as escolas}

Observa-se, no período, uma perda de importância nas políticas públicas da educação do fomento ao diálogo entre as instituições do setor, como vinha acontecendo no período anterior. Sofreram diminuição atividades como congressos, fóruns, oficinas, etc., realizadas nas escolas da rede pública de ensino básico com professores e demais funcionários visando a criação de espaços de debate que desenvolva nos profissionais aspectos de sensibilidade e criatividade com fines a fornecer uma educação inclusiva e de melhor qualidade na perspectiva da diversidade. (WATSON, p. 154).

As políticas desenvolvidas no período, das instituições públicas municipais, priorizaram a assistência do contingente imigrante $\mathrm{e}$ refugiado em idade adulta. Os Centros de Referência de Atendimento para imigrantes (CRAIs e Programas municipais, como o Portas Abertas ${ }^{10}$ ) e outras instituições, como as unidades SESCs, acolheram imigrantes e refugiados, jovens e adultos, oferecendo-lhes cursos de português e oficinas de empoderamento e treinamento direcionadas a encaminhá-los para o mercado de trabalho.

Impacto maior dessas políticas é evidenciado com relação à categoria de funcionários da educação, na precarização de suas condições

\footnotetext{
${ }^{10}$ Portas Abertas é iniciativa conjunta entre a Secretaria Municipal de Direitos Humanos e Cidadania - que atuou como motivadora do programa, devido à grande demanda das populações imigrantes em relação ao aprendizado da língua portuguesa - e a Secretaria Municipal de Educação. Em 2016, o Portas abertas forneceu aulas realizadas em 10 escolas na cidade de São Paulo, em regiões de alta vulnerabilidade e maior incidência da população imigrante (nas zonas Norte e Leste do município), com um total de 17 salas abertas e 360 alunos inscritos - a maioria composta por jovens/adultos entre 25 e 30 anos, vindos principalmente da América Latina, seguidos por africanos, europeus e asiáticos. Disponível em: https://fapss.br/noticias/programa-portas-abertas
} 
de trabalho. Eles vêm lutando, no conjunto do funcionalismo municipal, contra a perda de direitos pelas reformas em andamento, uma das quais, a implantação da SampaPrevi ${ }^{11}$, que modifica os termos da aposentadoria dos funcionários. Todas as escolas dos bairros em estudo participaram com adesão total ou parcial, de greves realizadas nos últimos anos pelo funcionalismo público.

Segundo declarações da maioria das responsáveis das escolas pesquisadas, as escolas da região mantiveram sua dinâmica nos últimos anos, não tiveram impacto das novas políticas na educação, como recorte de salas ou fechamento de unidades, como ocorrido em outros bairros da cidade $^{12}$. No entanto, a pesquisa constata diminuição do número de estudantes em três escolas estaduais do Brás, no EM, que se vincula à diminuição do número de vagas nas escolas (recorte de vagas e/ou salas) que se constata como uma das causas da política restritiva do estado. Porém, foi declarada uma certa preocupação respeito da redução de verbas anunciada para os próximos anos, pelo governo do estado, que implica na perda da capacidade de manutenção das unidades escolares.

Com relação a reformas maiores como a eliminação de disciplinas do currículo ou mudanças na perspectiva ideológica do processo pedagógico, como anunciado pela política federal, diretoras

${ }^{11}$ O Projeto de Lei (PL) 621/2016, que trata da reforma da previdência municipal e cria a São Paulo Previdência (SampaPrev), foi aprovado na Câmara Municipal em 26 de dez de 2018. O projeto define que a contribuição previdenciária dos servidores passará de $11 \%$ para $14 \%$. E passa a valer o mesmo teto da previdência federal: $\mathrm{R} \$ 5.600$. Os servidores novos serão incluídos em um sistema de previdência por capitalização. Os que já atuam no funcionalismo permanecem no sistema atual. Os que quiserem receber acima do teto deverão pagar uma contribuição adicional, entre $1 \%$ e $7 \%$ do valor que ultrapassar o teto.

${ }^{12}$ Alckmin reduz participação da Educação no orçamento pelo segundo ano - A gestão destina gastar em 2016, 13,5\% menos na despesa em Educação e 3,5\% nos salários dos funcionários. Essa redução nos recursos ocorre paralelamente a uma reorganização proposta da rede, que implica fechar 93 Escolas. Disponível em: http:// politicaseducacionaisnaimprensa.blogspot.com/2015/11/alckmin-reduz-participacaoda-educacao.html 
e coordenadoras pedagógicas não tem ainda uma percepção clara dos impactos, acharam muito cedo para ter uma opinião acabada.

\section{A infraestrutura das escolas}

Quase todas as unidades escolares funcionam em grandes prédios antigos, com amplos espaços para recreação. Nas creches constam instalações de jogos para as crianças. Segundo a coordenadora pedagógica de uma creche, as crianças gostam tanto do espaço que, no primeiro dia, levam um choque, mais depois que acostumam não querem mais sair da escola. Isso ocorre com a maioria das crianças, que vêm de moradias pequenas, espaços divididos em várias famílias, em prédios de invasão ou sendo criadas comprimidas, como as bolivianas que ficam sentadas no carrinho ou embaixo das máquinas, durante as longas horas que as mães trabalham nas oficinas de costura, segundo declaração de uma gestora.

\section{Rotatividade de diretores e gestores}

Em visita às escolas, observou-se também a mudança de diretores, vice-diretores e coordenadores pedagógicos na maioria dos centros escolares. Alguns foram transferidos para outras escolas e outros se aposentaram. Isso tem impacto na continuação, na direção adotada para tratar as questões e problemas da escola pelos professores e gestores. Experiências interessantes, realizadas em uma EMEI e uma EF, foram descontinuadas no período, por exemplo, as atividades visando a inclusão de minorias (indígenas, afrodescendentes e imigrantes) como proposta de professores. Por outro lado, foi relatada, pela coordenadora pedagógica da Creche Antônia Moutri Lamberga, a realização de uma visita anual dos professores, antes de iniciar as atividades escolares, à Rua Coimbra (localizada a poucos quarteirões da escola), onde eles podem apreciar a dinâmica da rua, os produtos da região andina oferecidos e entrar em 
contato com a população da Bolívia. Segundo ela, é um momento muito importante para os professores.

Surgem da iniciativa pessoal/individual de professores e/ ou gestores, as propostas e realização de ações nas escolas para lidar com questões específicas do âmbito educativo, como no caso das dificuldades dos estudantes estrangeiros, que trazem características culturais particulares, e que precisam de um outro olhar no atendimento da população escolar.

\section{Permanência na escola}

Nos estudos sobre o processo de aprendizagem, o absenteísmo e o abandono escolar aparecem como duas variáveis influenciadoras do desempenho escolar. Ao perguntar como se apresentava esses itens nas escolas pesquisadas, a resposta de professores e gestores foi unânime, "não é melhor nem pior que a dos nacionais, eles até têm mais comprometimento que muitos nacionais com a escola, agora...eles viajam, viajam várias vezes ao ano". Essa declaração levou a indagar sobre as viagens, confirmando-se a ocorrência do fato em várias escolas, inclusive em uma escola de Guarulhos, bairro da região Metropolitana de São Paulo, com importante proporção de população imigrante. (Molinari, p. 167). Na EE Prudente de Morais foi declarado entre 20 e 30 famílias ao ano que tiram os filhos da escola antes de terminar o ano letivo. Esse número de alunos constitui $6,4 \%$ do total de estudantes estrangeiros. $\mathrm{Na}$ escola Eduardo Prado, foi declarado que eles se deslocam várias vezes ao longo do ano, de preferência no mês de novembro.

Foi declarado que esse fato vem se incrementando nos últimos anos, e que antes os pais trancavam matrícula, o que não fazem mais. Alguns pedem para guardar a matrícula, mas isso não é possível porque 
as vagas são preenchidas na Secretaria de Educação, as escolas apenas disponibilizam as vagas. Alguns voltam no ano seguinte outros não. As famílias bolivianas têm esse costume mais arraigado, mas as peruanas também o estão praticando.

A justificativa desses deslocamentos ou viagens por parte dos pais são várias, por atendimento de saúde - eles alegam que foram marcadas cirurgias no país natal, problemas familiares, comemoração de festividades. A festa mais importante declarada é o Dia dos Mortos, que se comemora em novembro. Outras festividades importantes que são celebradas na Bolívia são em homenagem à Virgem de Urkupinha (agosto), Virgem de Copacabana (fevereiro e agosto), Virgem da Candelária (fevereiro), que congregam em torno de um milhão de paroquianos e turistas nacionais e internacionais.

\section{O Dia dos Mortos ${ }^{13}$}

O Dia dos Mortos é uma festa que cultiva a memória aos falecidos, constituindo uma data importante no calendário dos bolivianos e peruanos. A festa tem lugar nos dias 1 e 2 de novembro, mas sua preparação dura várias semanas e é coletiva (participa toda a família). Este ato demonstra a importância da reciprocidade na sociedade andina:

${ }^{13}$ Dia dos Mortos ou Festa de Finados ou Todos Santos é uma comemoração dos países hispano-americanos, no continente sul-americano se celebra na região andina. O dia 2 de nov., o dia principal, porém a festa mesma começa no dia anterior, ao meio-dia, quando as almas dos mortos chegam às casas para compartilhar com os vivos alegria $\mathrm{e}$ alimentos. O ritual é complexo, um exemplo do sincretismo entre tradição pré-colonial e tradição cristã importada pelos espanhóis. $\mathrm{Na}$ tradição pré-colonial quando uma pessoa morre, sua alma vai se "reunir com o mundo de baixo", de onde ela volta para o mundo dos vivos. No $1^{\circ}$ de novembro ao meio dia, as famílias dos mortos montam uma mesa sobre a qual dispõem uma toalha (branca se o morto é uma criança ou negra se é um adulto), por cima põem elementos simbólicos (objetos, foto do falecido, velas) e as comidas preferidas dos falecidos. A festa está vinculada ao calendário agrícola e cai no final da época seca. Disponível em: http://www.boliviacultural.com.br/port/artigo/diade-finados-dos-bolivianos-e-celebrado-de-maneira-distinta-dos-brasileiros 
os vivos alimentam os mortos cujos ossos estão a secar debaixo do sol e que os mortos intervenham para que a terra permita boas colheitas, e sobretudo que as chuvas, de novembro, sejam abundantes.

\section{A qualidade do ensino e as escolas na percepção das mães}

O que motiva as famílias levar os filhos de volta ao país de origem antes de concluírem o ano letivo? Estudos sobre o retorno das famílias imigrantes apontam várias razões: reunificação familiar, falta de trabalho, finalização dos estudos no país natal, deportações, etc.

No caso das famílias estudadas qual a percepção sobre a educação dos filhos?

Para bolivianos e peruanos a educação dos filhos é muito importante, é um meio de mobilidade social, na frase de uma mãe "a educação dos filhos é sagrada". Partindo dessa consideração procurouse indagar como era apreciada pelas famílias em questão a qualidade do ensino nas escolas da região. A maioria das mães declarou não estar satisfeita com o ensino oferecido aos filhos, de um lado, e de outro, a impossibilidade de tirar os filhos da escola por falta de alternativas, eles não têm condições de pagar uma escola particular. Duas respostas foram recorrentes respeito da escolaridade oferecida:

A primeira, que o ensino é "relaxado". Nesse caso elas comparam a educação oferecida nas escolas em São Paulo com a do país de origem (Bolívia ou Peru), indicando que o conteúdo do currículo é menos exigente, e também que se passa pouca tarefa para fazer em casa. Nesse aspecto a percepção pode se referir a que os professores se envolvem pouco com os problemas de aprendizagem dos estudantes estrangeiros, pois o aluno passa de ano de "qualquer jeito". Esse item se refere a que 
os alunos não podem ser reprovados nesses anos de escolaridade.

A segunda, que é "atrasada", no sentido que a criança é alfabetizada muito tarde em relação ao que ocorre nos outros países, onde as crianças aprendem a ler e escrever com menos idade.

Com fins a entender a decisão dos pais de levar os filhos da escola antes de terminarem ao ano letivo algumas possíveis explicações foram elaboradas:

1) os filhos são levados de volta para continuar os estudos no país natal; esta hipótese é apropriada no caso de alunos nos últimos anos do EM, mas ocorre com estudantes de todos os anos de escolaridade,

2) fazendo um balanço entre o vínculo familiar com a terra natal (familiares, costumes, festividades, etc.) e a educação que recebem os filhos, aquém do esperado, pode estar pesando mais o vínculo familiar, ou

3) a situação geral da família está incerta, então os filhos tem que entrar no mercado de trabalho, nesse caso o estudo fica postergado.

Dois aspectos estão na base dessas decisões, de um lado, no campo econômico, a flexibilização no sistema de trabalho no país (terceirização nas atividades da costura) e/ou a falta de trabalho (no marco de uma economia cada vez más recessiva como a brasileira no momento). De outro, a característica da família - transnacional - onde pais e filhos mantêm firmes os laços familiares embora morando em lugares longínquos, em países diferentes. A isso se soma a expansão, nessas comunidades, da tecnologia (uso de celulares, Internet) e a melhoria nos meios de transporte (as viagens cada vez mais curtas e baratas) ${ }^{14}$. Em todo caso, as famílias estariam atingindo um dos sonhos do imigrante, que é voltar para a terra natal, há que considerar que a Bolívia é um dos poucos países na região que, nos últimos anos, tem apresentado ${ }^{14}$ Faz unos 5 anos, Ormeño - linha de transporte terrestre peruana - opera no percurso Lima-São Paulo/Rio de Janeiro, passando pelo Cuzco (Peru). 
importante crescimento econômico.

As declarações de algumas mães imigrantes ilustram esses contextos. Uma peruana, mãe solteira, desempregada (trabalhou como comerciante e depois em um restaurante peruano), disse estar pensando voltar para o Peru, porque o trabalho caiu muito esses anos; outra peruana, comerciante, declarou ter voltado para o Peru uma vez, porque o filho tinha problemas na escola aqui, mas depois que retornou, ele está se dando bem, aprendeu muito lá (no Peru); e, uma boliviana, separada do marido, faxineira em casas particulares e mãe de três crianças nascidas na Bolívia, a maior veio com doze anos para o Brasil, declarou ter mandado a filha maior para terminar o Ensino Médio em La Paz, onde está com seu pai, porque não se identificava aqui, lá ela está feliz, e o plano da mãe é a filha fazer faculdade na Bolívia.

Resultados da Pesquisa: indicadores do desempenho escolar

Os temas abordados na pesquisa atual com os pais de família Aplica-se um questionário aberto para as notas obtidas nas disciplinas de português e matemática em 2018.

Nessa seção se pretende analisar aspectos da aprendizagem dos estudantes, abordando os resultados das avaliações das disciplinas Português e Matemática. Qual o desempenho escolar a partir do estudo das notas obtidas.

Sobre a amostra foi aplicado um questionário a 34 dos 39 pais dos estudantes selecionados (os outros cinco eram estudantes no Nível Inicial). A nacionalidade dos entrevistados: boliviana, peruana, argentina e brasileira (filhos de estrangeiros) ${ }^{15}$. Os resultados estão apresentados

${ }^{15} \mathrm{O}$ tamanho da amostra é pequeno devido à dificuldade de coleta da informação, início do ano letivo e ocorrência de greve do funcionalismo municipal. 
em gráfico, do português figuras 1 e 2 e de matemática figuras 3 e 4 . Os resultados:

Uma primeira constatação, todos os estudantes entrevistados tanto no nível de EF quanto no EM têm melhores avaliações em matemática que em português. No EM $25 \%$ dos entrevistados chegam a obter 10 , a nota máxima.

Estudantes nascidos no Brasil, de pais estrangeiros, têm melhor desempenho nas duas disciplinas, pois atingem as maiores avaliações. Isso ocorre inclusive nas famílias onde o entrevistado tem irmão ou irmã que nasceu no país de origem ou emigrou na adolescência. Fato que se corrobora com declarações dos pais, que o filho não teve problemas com o idioma, pois ele veio pequeno para o Brasil ou que ela/e fala direitinho o português porque nasceu aqui.

\section{Avaliações de português}

Numa escala de 6 a 10, a nota 6 aglutina $41 \%$ dos estudantes entrevistados do EF contra $20 \%$ do EM. Considerando o item Não Declarada (ND), 4\%, o valor no EF atinge $45 \%$ dos estudantes entrevistados. Nas entrevistas, algumas declarações foram, "minha nota no português foi de 5 para 6". A declaração ND foi registrada quando o entrevistado não teve coragem de falar a nota no momento da entrevista.

$\mathrm{Na}$ nota 7 se observa o oposto, sendo $18 \%$ nos estudantes do EF contra $40 \%$ no EM. Esse dado estaria indicando maior dificuldade com o conteúdo da língua portuguesa nos primeiros anos do ensino. Professores indicam a dificuldade dos estrangeiros ainda no nível inicial, na alfabetização, ao lidar com a língua portuguesa.

As maiores notas 9 e 10 agrupam o $18 \%$ no nível de EF, sendo inexpressivo este item no EM. Do total de estudantes questionados, quatro declararam ter recebido reforço escolar, desses três estrangeiros 
e um brasileiro filho de bolivianos; dois, de nacionalidade boliviana, declararam ter sido encaminhados para ajuda psicológica, um deles por causa de bullying.

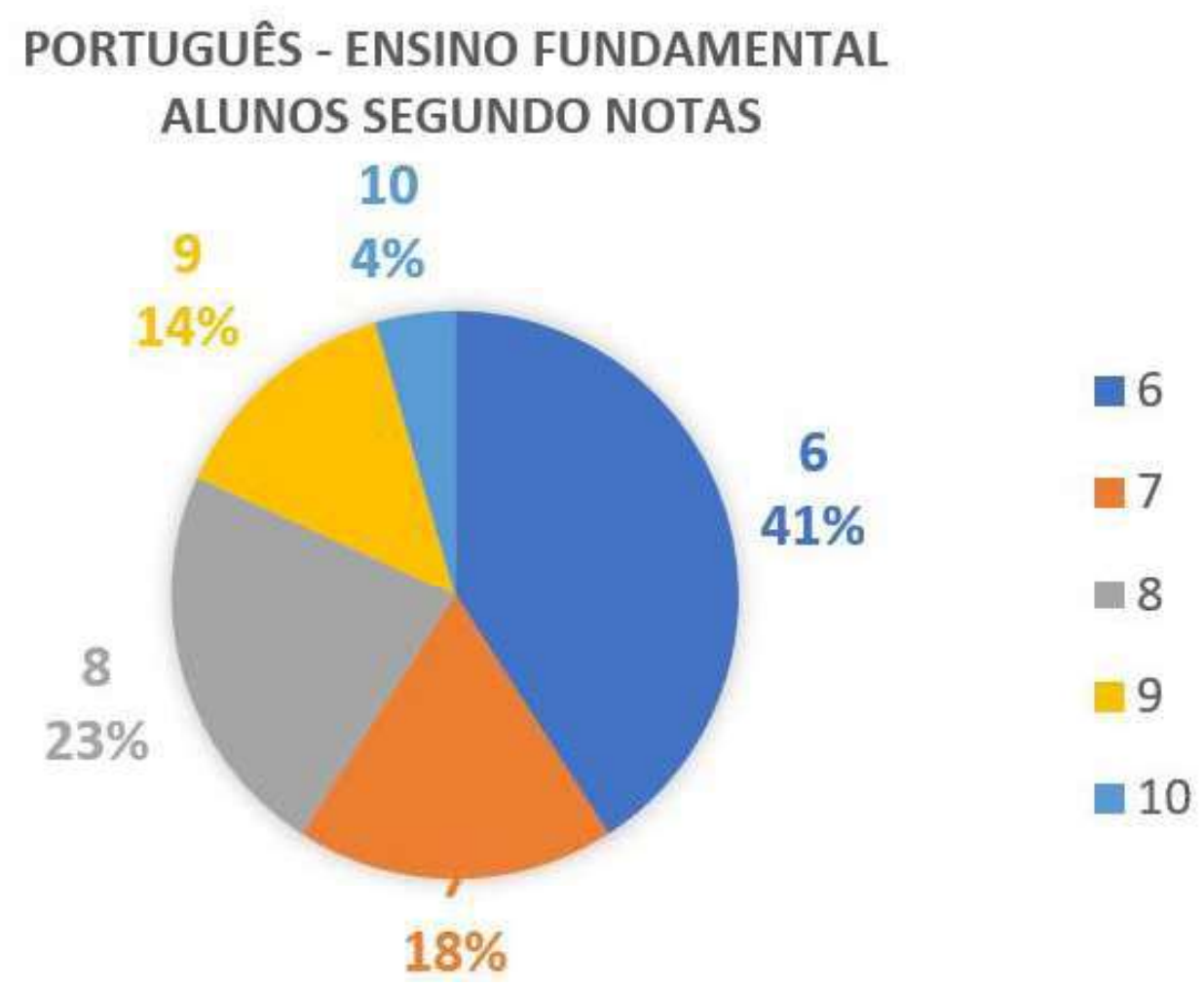

Fonte: Elaborado pela autora.

Gráfico 1 - Notas em Português no Ensino Fundamental

Português - Ensino Médio

Alunos Segundo Notas

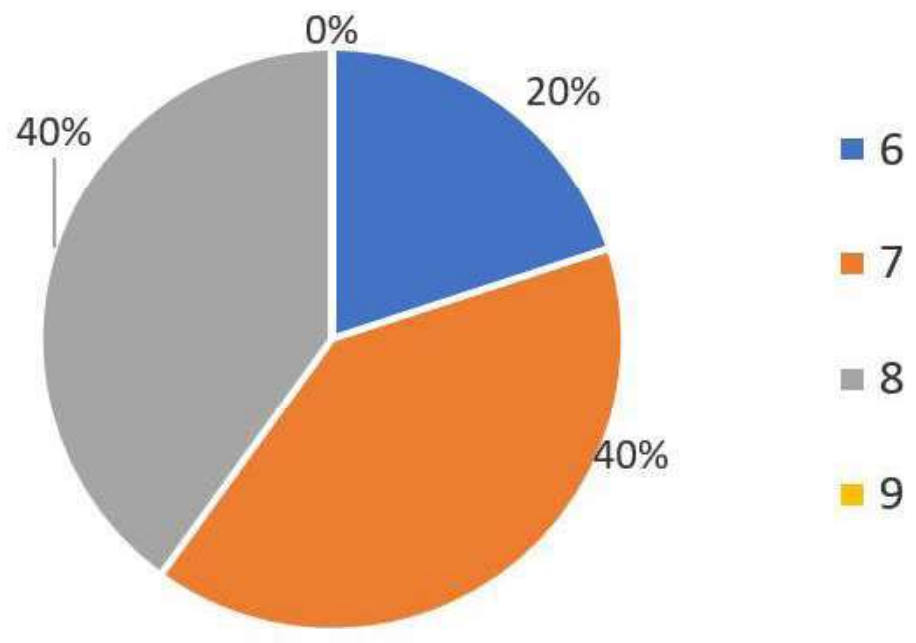

Fonte: Elaborado pela autora.

Gráfico 2 - Notas em Português no Ensino Médio 
Avaliações de matemática

Em matemática os resultados são bem diferentes dos encontrados no português. A nota 6 agrupa 12\% dos estudantes do EF e 15\% do EM. As maiores proporções dos entrevistados correspondem às notas 9 e 10, com $51 \%$ no EF e $48 \%$ do EM.

Os resultados acima podem estar apontando uma maior facilidade de aprendizagem do raciocínio matemático por parte dos estudantes estrangeiros; no caso de uma língua, os aspectos são mais complexos, além da fonética, têm estruturas gramaticais como conjugação de verbos, etc.

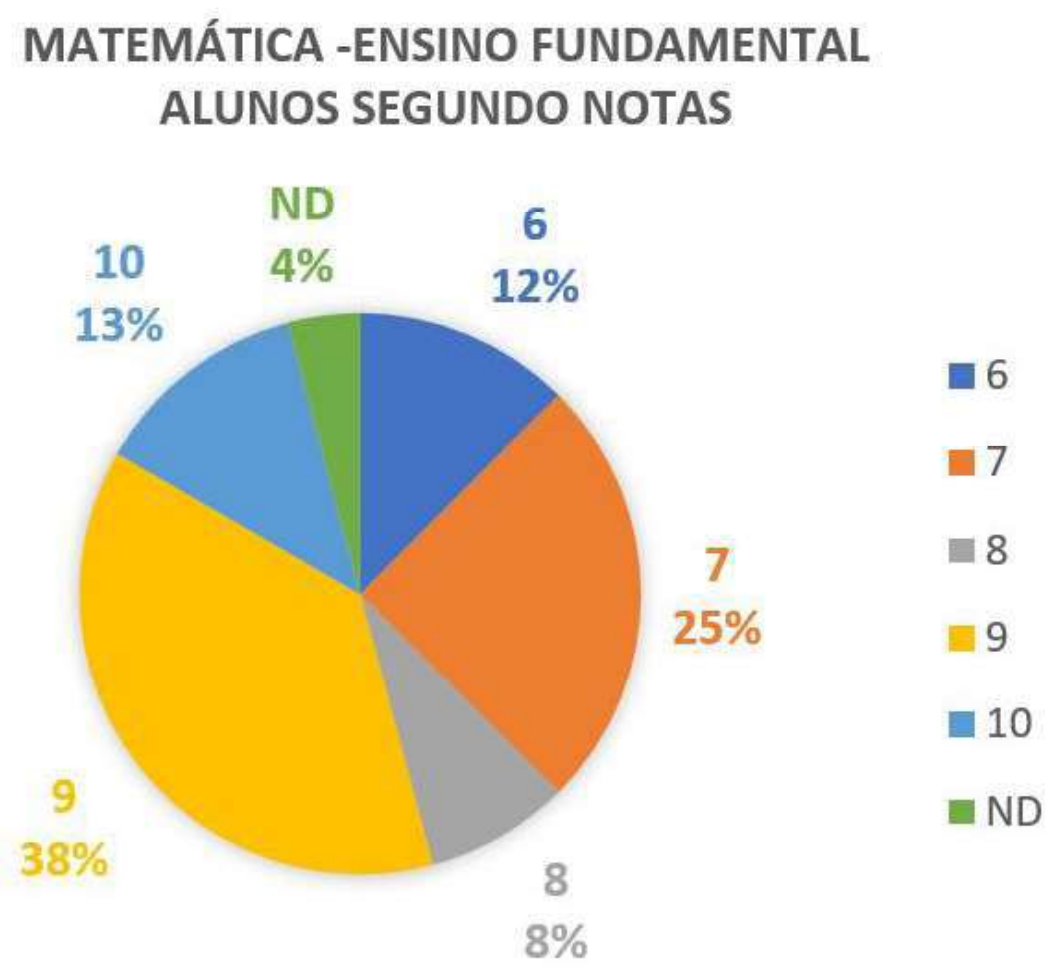

Fonte: Elaborado pela autora. 


\section{Alunos Segundo Notas}

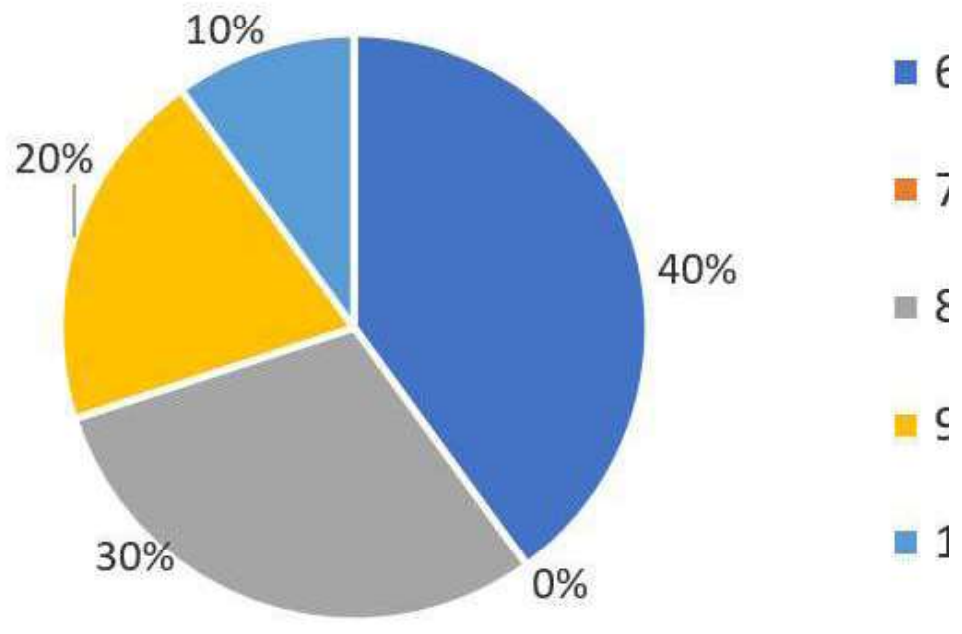

Fonte: Elaborado pela autora.

\section{Gráfico 4 - Notas em matemática no Ensino Médio}

Esses resultados corroboram resultados de outros estudos, que constatam que estudantes estrangeiros da rede pública de ensino apresentam menos problemas e, portanto, têm um melhor desempenho escolar em matemática que em português ${ }^{16}$.

E, de outro lado, estudos que indicam a dificuldade de aprendizagem por parte de estudantes estrangeiros, como de congoleses, num bairro de Rio de Janeiro; motivada pela língua diferente e pela falta de diretrizes das instituições de ensino que orientem os professores no trabalho com estes alunos. (PETRUS, 2016, pp. 45).

${ }^{16}$ No processo de alfabetização de crianças numa escola de Guarulhos, vários professores relatam sua preocupação em relação aos imigrantes bolivianos e o idioma, não foi mencionado dificuldades com matemática. Uma professora diz de uma estudante boliviana: “...nas atividades de escrita espontânea ela melhorou muito. Em Matemática está superbem.” (Molinari, 2017, p. 172). 


\section{Considerações finais}

Os resultados da pesquisa não foram os esperados segundo a tendência apontada no estudo anterior no que diz respeito ao aspecto escolar. Se constatou diminuição da população escolar na região em foco, com maior taxa no bairro do Brás; e diminuição da população escolar estrangeira no Bom Retiro. Aconteceu realocação de estudantes estrangeiros de umas escolas para outras no mesmo bairro. Os motivos será objeto de pesquisa posterior.

As condições da educação da população escolar boliviana e peruana pode estar sendo afetada pela situação de vulnerabilidade das famílias que se vêm obrigadas a retirar seus filhos das escolas em qualquer momento do ano, antes do término do ano letivo. Tudo isso acontece em um contexto em que se observa uma diversificação das nacionalidades entre a população escolar; no qual o segmento de bolivianos sofre diminuição e o de paraguaios e peruanos acréscimo.

Se observou uma dinâmica económica intensa na região, com a consolidação de atividades de costura, comercio e recentemente de gastronomia e salões de beleza.

Com relação à pesquisa direta relativa ao desempenho escolar, os níveis de rendimento dos estrangeiros é de mediana para baixo, fato que ocorre com outros grupos de estrangeiros. Segundo as declarações, se observou os professores não terem uma percepção das diferenças (culturais, de língua, etc.) entre os estudantes nativos (brasileiros) e os de outras nacionalidades e o impacto no seu trabalho com estudantes estrangeiros. Os pais comparam o ensino nas escolas no Brasil às das escolas no país de origem e acham que aqui fica aquém do esperado. 


\section{Referências Bibliográficas}

ALVITES, L. - Madres e hijos/as de locutorio, Editorial Perú Migrante, Lima, Perú, 2001 Disponível em: https://plazadearmascl.blogspot. com/2010/08/madres-de-locutorio-peruanas-en-chile.html Acesso em: 1 mar. 2019.

BAENINGER, R. \& FERNANDES (org.) - Migrações Sul-Sul. Campinas, São Paulo: NEPO, 2018.

BAHIA, J; SANTOS, M. (org.) - Um olhar sobre as diferenças: a interface entre projetos educativos e migratórios. São Leopoldo: Oikos, 2016. .

Banco Internacional de Reconstrucción y Fomento/Banco Mundial Migración desde Venezuela a Colombia: impactos y estrategia de respuesta en el corto y mediano plazo. Washington, D.C. 2018 www.bancomundial. org/co Disponível em: https://openknowledge.worldbank.org/bitstream/ handle/10986/30651/131472SP.pdf?sequence $=3 \&$ isAllowed=y. Acesso em: 1 nov. 2018

Cidade Escola Aprendiz Programa Cidades Educadoras. EMEI João Theodoro s/d. Disponível em: https://cidadeseducadoras.org.br/especiais/ infancias-migrantes-em-sao-paulo/wp-content/uploads/2018/12/ DIAGNÓSTICO_BAIRRO-ESCOLA_LUZ-BOM-RETIRO_2017.pdf. Acesso em: 30 maio 2019.

COTINGUIBA, G.C.; Cotinguiba, M.L.P. - Balanço e reflexões sobre a Imigração Haitiana no Brasil: um ensaio. Caderno de Debates Refúgio, Migrações e Cidadania, v.12, n.12, Brasília, 2017.

HAMANN, E.T. \& HARKLAU, L. - Education in the New Latino Diaspora In: Handbook in Latinos and Education: Theory, Research and Practice, New York \& London: Routledge, 2010 pp. 157-169.

MAGALHÃES, L.F.A. et al. Migrantes e Refugiados Sul-Sul na cidade de São Paulo: Trabalho e espacialidades In: Migrações Sul-Sul, Campinas: 2018 pp. 402-419.

MAZZA, D.; NORÕES, K. (org.) - Educação e migrações internas e 
internacionais- Um diálogo necessário. Jundiaí, Paco Editorial, 2016

MOLINARI, S.G.S. - A escolarização de imigrantes bolivianos no município de Guarulhos In Imigração atual: dilemas, inserção social e escolarização Brasil Argentina e EUA/Leda Maria de Oliveira Rodrigues (org.). São Paulo: Escuta 2017

PETRUS, R.; SANTOS, M.; ARAGÃO, L.X. de - Filhos de refugiados congoleses no Rio de Janeiro: socialização e escolarização nas escolas da rede pública de ensino In BAHIA, J; SANTOS, M. (org.) - Um olhar sobre as diferenças: a interface entre projetos educativos e migratórios. São Leopoldo: Oikos, 2016. pp.35-55

RODRIGUES, G.M.A.; Sala, J.B. - Refugiados sírios no Brasil, políticas de proteção e integração In: Migrações Sul-Sul, Campinas: 2018 pp. 309324)

RODRIGUES, L.M. de O (org.) - Imigração atual: dilemas, inserção social e escolarização Brasil Argentina EUA. São Paulo: Escuta 2017

SILVA, C.R. da - Migração de Venezuelanos para São Paulo: Reflexões iniciais a partir de uma análise qualitativa In Migrações Sul-Sul: Baeninger \& Fernandes (org.). Campinas: 2018, pp. 356-367

SEADE, Fundação Sistema Estadual - Portal de estatísticas do Estado de São Paulo: 2018 Disponível em: http://produtos.seade.gov.br/produtos/ projpop/index.php. Acesso em 30 maio 2019.

WATSON, C. de - Imigrantes Latinos e Escolas Públicas em dois Bairros da Cidade de São Paulo: Bom Retiro e Brás In Identidade e Diversidade Cultural na América Latina. Lima, E. \& Watson, C. de (org.), Porto Alegre: Editora Fi 2017, pp. 151-170. 